\title{
REFERENCE POINTS FOR THE STRUCTURAL REFORM OF THE ACADEMIC TEACHING STAFF DEVELOPMENT IN ROMANIA WITHIN CO-FUNDED PROJECTS UNDER POSDRU 2007 - 2013 AND POCU 2014-2020
}

REPERE DE REFORMĂ STRUCTURALĂ ÎN DOMENIUL FORMĂRII PSIHO-PEDAGOGICE A CADRELOR DIDACTICE UNIVERSITARE DIN ROMÂNIA PRIN PROIECTE COFINANȚATE DIN POSDRU 2007 - 2013 ȘI POCU 2014-2020

\section{Dorina Dumitra ZLOTA}

Journal of Pedagogy, 2018 (2), 127 - 137

https://doi.org/10.26755/RevPed/2018.2/127

The online version of this article can be found at: http://revped.ise.ro/category/2018-en/

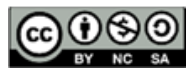

This work is licensed under the Creative Commons Attribution-NonCommercial-ShareAlike 4.0 International License. 94042, USA.

Published by:

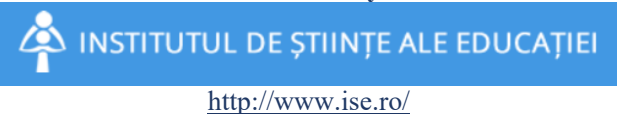

http://www.ise.ro/

Further information about Revista de Pedagogie - Journal of Pedagogy can be found at:

Editorial Policy: http://revped.ise.ro/editorial-policy/

Author Guidelines: http://revped.ise.ro/the-writer-guide-2/ 


\title{
REPERE DE REFORMĂ STRUCTURALĂ ÎN DOMENIUL FORMĂRII PSIHO-PEDAGOGICE A CADRELOR DIDACTICE UNIVERSITARE DIN ROMÂNIA PRIN PROIECTE COFINAN ATE DIN POSDRU 2007 - 2013 ŞI POCU 2014 - 2020
}

\author{
Dorina Dumitra Zlota* \\ Ministerul Educa iei $\mathrm{Na}$ ionale \\ Bucureşti, România \\ dorinazlota@yahoo.com
}

\section{Rezumat}

Scopul analizei realizate a fost determinat de necesitatea identificării stadiului de reformă structurală în domeniul formării psiho-pedagogice, ini ială şi continuă, a cadrelor didactice din învă ământul superior, inclusiv a formatorilor de formatori, adică a acelor cadre didactice care au atribu ii în formarea viitoarelor cadre didactice universitare sau a personalului didactic din învă ământul preuniversitar, prin proiecte cofinan ate din Programul Opera ional Sectorial Dezvoltarea Resurselor Umane 2007-2013 (POSDRU).

Spre deosebire de situa ia unei oferte consistente de programe de formare psihopedagogică continuă destinate personalului didactic din învă ământul preuniversitar, se constată existen a unei palete mult mai restrânse de oferte de formare pentru cazul cadrelor didactice din învă ământul superior. Prin urmare, prima ini iativă de reformă structurală în domeniul formării psihopedagogice continue destinate personalului didactic universitar se doreşte a fi continuată şi prin Programul Opera ional Capital Uman 2014 - 2020 (POCU) şi devine tot mai necesară în contextul în care o premisă de prim ordin pentru eficientizarea sistemului românesc de educa ie şi formare profesională, este reprezentată de calitatea investi iei în resursa umană implicată în educa ia genera iilor actuale şi viitoare de elevi şi studen i.

Cuvinte-cheie: Cadre didactice, formare continuă, fromare ini ială, interven ii POCU, proiecte POSDRU

* Dr., Ministerul Educa iei Na ionale, Bucureşti, România. 


\begin{abstract}
The purpose of the analysis was determined by the need to identify the stage of structural reform in the field of initial and continuing psycho-pedagogical education of teachers in higher education, including the trainers of trainers, meaning those teachers who have attributions in the formation of future academic staff or staff didactic education in pre-university education through co-financed projects from the Operational Program - Human Resources Development (POSDRU) 2007 - 2013.

Such a structural reform is intended to be continued through the Operational Program Human Capital (POCU) and becomes increasingly necessary in the context in which a prerequisite for the efficiency of the Romanian education and training system is represented by the quality of investment in the human resource involved in the education of current and future generations of students for all education levels.
\end{abstract}

Keywords: Continuous training, teachers, initial training, POCU interventions, POSDRU projects.

\title{
1. Considera ii preliminare
}

Pe parcursul exerci iului financiar 2007 - 2013, în cadrul Domeniului Major de Interven ie (DMI) 1.3., Axa Prioritară (AP) 1 din Programul Opera ional Sectorial Dezvoltarea Resurselor Umane (POSDRU) din România, conform descrierii DMI 1.3. din cadrul Documentului Cadru de Implementare pentru POSDRU 2007 - 2013 (MFE 2015, p. 36), s-a asumat la nivel na ional faptul că „,vor fi sus inute activită ile de creştere a accesului şi participării cadrelor didactice la programele de masterat, în special masteratele pedagogice şi transdisciplinare pentru profesori, dezvoltarea şi furnizarea de programe de formare ini ială pentru cadre didactice şi formatori, inclusiv masterate pedagogice şi transdisciplinare".

Perspectiva de ac iune strategică s-a înscris în obiectivul general al axei prioritare 1 din POSDRU, referitor la: ,dezvoltarea rutelor flexibile de învă are pe tot parcursul vie ii şi creşterea accesului la educa ie şi formare prin furnizarea unei educa ii ini iale şi continue moderne şi de calitate, incluzând învă ământul superior şi cercetarea" (MMFEŞ - POSDRU, p. 68).

În vederea asigurării acestui deziderat, în cadrul interven iilor finan ate pentru 
DMI 1.3. (A.P.1), au fost programate: „Formarea şi perfec ionarea profesorilor, formatorilor şi a altor tipuri de personal didactic din educa ie şi formare profesională continuă, inclusiv formarea şi perfec ionarea în parteneriat cu companii” (MMFEŞ - POSDRU).

Pe aceste baze programatice, ,,eforturile avute în vedere pentru îmbunătă irea formării ini iale a profesorilor vor fi completate cu ac iuni de dezvoltare a unei oferte flexibile de formare continuă. Formarea profesorilor va viza, atât pregătirea pedagogică, cât şi metodica disciplinei. Ca parte a ac iunilor de îmbunătă ire a sistemelor de educa ie şi formare, precum şi pentru asigurarea accesului egal la educa ie, sprijinul din Fondul Social European (FSE) va viza dezvoltarea programelor de formare şi perfec ionare specifice pentru noile profesii în educa ie şi formare, a programelor de formare şi perfec ionare a profesorilor în domenii legate de ocupa ii noi şi a celor derulate în parteneriat cu companii".

\section{Interven ii cofinan ate FSE prin proiecte POSDRU 2007-2013 în domeniul formării psiho-pedagogice, ini ială şi continuă a cadrelor didactice din învă ământul superior}

Scopul analizei realizate a fost determinat de necesitatea identificării stadiului de reformă structurală în domeniul formării psiho-pedagogice a cadrelor didactice din învă ământul superior, inclusiv din perspectiva formării formatorilor de formatori, adică a acelor cadre didactice care au atribu ii în formare a viitoarelor cadre didactice universitare sau a personalului didactic din învă ământul preuniversitar.

O astfel de reformă structurală devine necesară în contextul în care o premisă de prim ordin pentru eficientizarea sistemului românesc de educa ie şi formare profesională, este reprezentată de creşterea calită ii resursei umane implicate în educa ia genera iilor actuale şi viitoare de elevi şi studen i, calitate aflată în corelare directă cu utilizarea unor abordări, metode şi instrumente pedagogice adecvate nevoilor formabililor. 
În sprijinul colectării datelor necesare, s-a utilizat metoda analizei documentelor generate din implementarea proiectelor cofinan ate din programul POSDRU 2007 - 2013, aflate în gestiunea Organismului Intermediar POSDRU din cadrul Ministerului Educa iei Na ionale, în special statistici institu ionale şi livrabile generate în cadrul proiectelor.

\section{Observa ii de ordin cantitativ}

În cadrul Domeniului Major de Interven ie (DMI) 1.3., Axa Prioritară (AP) 1 din POSDRU din România (MMFEŞ - POSDRU), au fost cofinan ate din FSE, pentru perioada 2007 - 2013, 11 proiecte (4 proiecte de grant şi 7 proiecte strategice) care s-au adresat grupului intă format din cadre didactice din învă ământul superior, în vederea realizării unor obiective de dezvoltare profesională ini ială şi continuă.

Valoarea totală a grupului intă anticipat ini ial a fost, pentru cele 11 proiecte analizate, de 3.754 persoane, valoarea realizată efectiv fiind de 6.682 persoane, constatându-se o depăşire cu 78\% a valorii grupului intă planificat, ceea ce semnifică şi o utilizare eficientă a fondurilor alocate, depăşirea fiind realizată în limita bugetului alocat ini ial.

Raportat la numărul total de 155 proiecte contractate în cadrul DMI 1.3., respectiv la alocarea financiară disponibilă pentru acest DMI pentru perioada 2007 - 2013, în valoare de 206.517.089 euro, se poate constata faptul că numărul de proiecte adresate formării ini iale/continue a cadrelor didactice din învă ământul superior a fost unul restrâns, dintre acestea 10 proiecte fiind ini iate de universită i, un singur proiect fiind propus şi derulat de către Ministerul Educa iei şi Cercetării Ştiin ifice, ca lider de parteneriat.

Din perspectiva specificului cursurilor de formare dezvoltate în cadrul celor 11 proiecte, remarcăm faptul că, în doar 2 dintre proiecte s-au dezvoltat şi furnizat cursuri de pregatire profesională continuă în domeniul specializărilor cadrelor didactice (în domenii cum ar fi: ingineria mediului, industria alimentară şi protec ia mediului, formarea specialiştilor în reabilitare orală etc.), în 10 dintre proiecte, majoritatea interven iilor de formare fiind realizate în domeniul didacticii specialită ii, al psihopedagogiei sau a cercetării avansate. Se observă aşadar, o nevoie consistentă de schimbare a abordărilor educa ionale necesare activită ilor didactice specifice cadrelor didactice din medii universitare. 


\section{Elemente de inovare calitativă, finan ate în cadrul proiectelor derulate}

Tematicele de formare continuă în domeniul didacticii specialită ii şi al psihopedagogiei regăsite în cadrul celor 10 proiecte finan ate au avut în vedere: formarea şi dezvoltarea materialelor didactice, managementul resurselor umane din învă ământul superior, concepte avansate de predare, cursuri virtuale de elearning, noi tehnologii pentru activită i de cercetare, formare continuă pe tema pedagogiei universitare, învă area centrată pe student, practica profesională a studen ilor (strategii institu ionale de proiectare, implementare şi evaluare a practicii profesionale a studen ilor plasamente şi parteneriate), dezvoltarea şi furnizarea unui modul de curs destinat profesorului supervizor, precum şi a unui curs de practică tehnologică etc.

În 2 dintre proiecte s-au dezvoltat şi furnizat cursuri postuniversitare de formare continuă cu tematică referitoare la ,Formare în blended learning şi tehnici educa ionale moderne pentru învă ământul universitar (DidaTec)”, „Calitate, inovare, comunicare în sistemul de formare continuă a didacticienilor din învă ământul superior", în alte 2 proiecte implementate fiind pilotate un program de master pedagogic (Master Academia), respectiv un program de formare continuă, acreditat de Autoritatea Na ională pentru Calificări, adresat cadrelor didactice din învă ământul superior, cu 2 componente: didactică şi pedagogie universitară, respectiv cercetare ştiin ifică avansată.

Din perspectiva modalită ilor de formare utilizate în cadrul proiectelor, remarcăm prezen a majoritară a modulelor de curs dezvoltate în cadrul proiectelor furnizate în forma tradi ională ,fa ă în fa ă”, combinată cu sesiuni online de formare în cadrul unor comunită i virtuale create, de tipul Master Academia, portalul InfoDidactic, platforma integrată suport DidaTec (cu un sistem de stocare şi arhivare a materialelor educa ionale în format electronic), Universitaria (platforma web pentru dezvoltarea oportunită ilor de progres în cariera universitară) etc.

Scopul declarat al platformelor/portalurilor dezvoltate în cadrul acestor proiecte a fost acela de a sprijini constituirea unei comunită i universitare na ionale şi transna ionale, cel mai adesea utilizându-se conturi individuale de acces care permit elaborarea/gestionarea/vizualizarea documentelor elaborate/utilizate în cadrul proiectelor. S-a ini iat, astfel, o infrastructură privind Tehnologia 
Informa iei şi Comunica iilor (ICT) destinată învă ării bazată pe module de e-learning, echipamente de videoconferin ă, alte facilită i de învă are şi comunicare în mediu virtual.

Lista modalită ilor de formare continuă a cadrelor didactice din mediul universitar este completată de: conferin e interuniversitare, vizite de studii pentru schimburi de experien e şi bune practici interna ionale, concursuri de proiecte elaborate de cursan i, workshop-uri tematice, realizarea de ghiduri de bune practici, elaborarea de articole ştiin ifice (cu indexare în baze de date interna ionale), seminarii de dezvoltare platforme e-learning, editare de lucrări de specialitate.

Regăsim în cadrul proiectelor şi preocuparea pentru ini ierea unor servicii specializate de tipul cabinete de didactică (organizat pe comisii didactice, include şi mentorii de practică sau stagiatură), centre de resurse, dar şi a unor evenimente na ionale dedicate, cum ar fi: conferin a na ională de didactică, Academia de vară etc.

În legătură cu aria de aplicabilitate a rezultatelor ob inute în aceste proiecte (ex: module de curs, comunită i ICT create, lucrări şi articole de specialitate, sugestii de reformare în domeniu etc.), la nivel na ional, este dificil de apreciat extinderea reală în condi iile în care domeniul formării ini iale şi continue (de tip psihopedagogic şi al didacticii specialită ii) pentru cadrele didactice din învă ământul superior este reglementat institu ional şi func ional, preponderent la nivelul universită ilor.

\section{Aprecierea tendin ei de construire a unor modele coerente de formare psihopedagogică a cadrelor didactice universitare}

Devine observabil faptul că nu există un factor de unificare a celor mai eficiente modele de formare psihopedagoică ini ială a cadrelor didactice care vor activa în învă ământul superior, inclusiv a celor care formează viitoare cadre didactice pentru învă ământul preuniversitar. Mai mult, cadrele didactice universitare nu beneficiază de un program sistematic şi unitar, la nivel na ional, de formare continuă psihopedagogică, program care să fie organizat şi furnizat 
periodic prin care să se propage în mod coerent abordări de politică educa ională promovate la nivel strategic pe termen mediu sau lung în cadrul unui demers de punere în practică a formării unui model de personalitate dezirabil în România pentru genera ii viitoare de absolven i.

Această remarcă este sus inută şi de concluzii exprimate de exper ii care au contribuit la derularea proiectelor analizate. De pildă, a fost constatată nevoia „realizării unei concep ii unitare pentru formarea didacticienilor pentru învă ământul superior, precum şi a asigurării unui cadru normativ coerent privind formarea didacticienilor" (conform contribu iilor pentru livrabile din cadrul proiectului de rulat de MEN, POSDRU 87/1.3/S/63709 - „Calitate, inovare, comunicare în sistemul de formare continuă a didacticienilor din învă ământul superior”). La fel de utilă devine şi constituirea unei re ele de specialişti cu atribu ii în designul pilonilor de formare psihopedagogică ini ială şi continuă pentru cadrele didactice universitare, piloni adecva i unui model logic de politică educa ională în domeniu.

Un model logic de formare psihopedagogică ini ială şi continuă a cadrelor didactice din învă ământul superior ar trebui să se fundamenteze pornind de la o analiză ex-ante, bazată pe rela ia dintre universită i, studii de dinamică a pie ei muncii, corelate cu studii de monitorizare a inser iei socio-profesionale a absolven ilor, a nevoilor formabililor, precum şi cu analize de nevoi, cu implicarea participării unor reprezentan i ai angajatorilor. O analiză ex-ante ,poate arăta limitările şi posibilită ile schimbării, dar poate eviden ia totodată şi consecin ele pentru diverşi actori sociali”'(Niklasson 2015, p. 36).

În plus, o astfel de analiză ar trebui să provină şi din concluzii ale panelurilor de exper i, utile pentru anticiparea unor scenarii de percepere a schimbărilor, cu implicarea actorilor direct interesa i de rezultatele acestor procese. Această propunere este sus inută şi de F. Singer şi L. Sarivan care afirmă că ,,plusurile şi minusurile realizării programului masteral (MasterProf) au legătură cu resursa umană implicată în cele trei grupuri intă ale proiectului (universitari, studen i/absolven i, personal de predare din unită i de aplica ie)" (Singer \& Sarivan, 2011), unii dintre aceştia fiind deschişi la inovare în timp ce al ii, mai pu in.

În cadrul unei analize ex-ante ar trebui să identificăm surse şi criterii pentru elaborarea standardelor pentru formarea personalului didactic universitar 
(Iucu, Borzea, \& Mironov), printre acestea regăsindu-se: standarde curriculare în rela ie cu politici educa ionale raportate la un model valoric, un sistem de roluri profesionale ale cadrelor didactice, specificul disciplinelor de învă ământ, etapele dezvoltării profesionale/evolu iei în carieră, paradigme/ modele explicative ale eficacită ii/eficien ei profesionale ale cadrelor didactice universitare, evolu ia ştiin elor educa iei, dezvoltarea cercetărilor specializate.

\section{Tendin e spre coeren ă prin viitoare interven ii cofinan ate FSE în cadrul pocu 2014 - 2020 în domeniul formării continue psiho-pedagogice a cadrelor didactice universitare}

În contextul Programului Opera ional Capital Uman 2014 - 2020 care ,stabileşte priorită ile de investi ii, obiectivele şi ac iunile asumate de către România în domeniul resurselor umane, continuând investi iile realizate prin FSE în perioada 2007-2013", interven iile de reformare a domeniului formării psihopedagogice, ini iale şi continue, a cadrelor didactice din mediul universitar este necesar să îşi focalizeze, tematic şi strategic, consisten a demersurilor.

Remarcăm în acest sens, pregătirea şi lansarea în anul 2018 a două apeluri de proiecte în cadrul Priorită ii de Investi ii 10.2. (din Axa prioritară 6 „Educa ie şi competen e" a POCU), adresate în principal sus inerii studen ilor din categorii vulnerabile sau sprijinirii integrarii profesionale a viitorilor absolven i prin programe de învă ate antreprenorială, apeluri care con in şi o semnificativă componentă de formare psihopedagogică continuă adresată cadrelor didactice universitare.

Astfel, în cadrul apelului de proiecte „Bursa student antreprenor - măsură activă pentru creşterea participării studen ilor din categorii vulnerabile la programe de studii de licen ă" (MFE 2018), profesorii din grupul intă al fiecărui proiect depus vor beneficia în mod obligatoriu de ,un program de dezvoltare de competen e didactice în cadrul unui program postuniversitar de perfec ionare profesională cu o durată de minim 56 ore de formare, din care minim 50\% vor reprezenta aplica ii practice" (MFE 2018, p. 8), programele de formare furnizate fiind centrate pe „activită i de formare 
specifică adresate personalului didactic din învă ământul superior în rela ie cu: proiectarea modulară de cursuri antreprenoriale adresate studen ilor, în special din categorii vulnerabile, din anii terminali ai ciclului de licen ă, organizarea şi furnizarea în medii online a cursurilor/aplica iilor şi promovarea de medii noi de învă are (ex.: studii, învă are bazată pe proiecte reale, învă are colaborativă, experimentare etc.), solicitarea şi utilizarea feedback-ului şi o evaluare eficientă a rezultatelor învă ării, servicii suport pentru studen i etc." (MFE 2018, p. 8).

Pentru apelul de proiecte „Măsuri de optimizare a ofertelor de studii din învă ământul superior în sprijinul angajabilită ii”, pentru ,fiecare participant din grupul intă reprezentat de personal didactic este obligatorie frecventarea a cel pu in unui program de dezvoltare de competen e didactice pentru care se acordă credite de studii transferabile, în cadrul unui program postuniversitar de formare” (MFE 2018, p. 10), fiind sus inute ,,activită i de formare specifică adresate personalului didactic din învă ământul superior în rela ie cu: proiectarea de cursuri complementare, organizarea şi furnizarea în medii online a cursurilor/aplica iilor şi promovarea de medii noi de învă are (ex.: studii de caz, învă are bazată pe contexte reale de ac iune, învă are colaborativă, experimentare etc.), solicitarea şi utilizarea feedback-ului şi o evaluare eficientă a rezultatelor învă ării, servicii suport pentru studen i etc." (MFE 2018, p. 9).

Devine observabilă, pe baza datelor de mai sus, tendin a de abordare unitară şi coerentă a formării de tip psihopedagogic a cadrelor didactice din învă ământul universitar, în rela ie cu temele principale ale celor două apeluri de proiecte POCU, stimularea învă ării antreprenoriale la studen i, respectiv adaptarea ofertelor de studii din învă ământul superior la nevoile de învă are ale studen ilor din categorii vulnerabile.

\section{Concluzii şi recomandări finale}

Enun ăm, în încheiere, câteva posibile interven ii necesare pentru domeniul supus analizei:

- Implicarea formabililor (cadre didactice universitare, studen i la Departamentul de Pregătire a Personalului Didactic, cadre didactice care 
supervizează practica pedagogică etc.) în identificarea de solu ii de optimizare a formării psihopedagogice ini iale şi continue, în sprijinul promovării reale a unei învă ări centrate pe student, care să conducă mai facil la personalizarea rolurilor didactice;

- Organizarea de paneluri de exper i pe tema reorganizării unitare a formării psihopedagogice ini iale şi continue a cadrelor didactice din învă ământul superior care să furnizeze input-uri relevante pentru decizii de sistem la nivelul Ministerului Educa iei Na ionale;

- Ini ierea interoperabilită ii platformelor ICT dezvoltate în proiecte anterioare cu cofinan are din POSDRU 2007 - 2013 pentru sustenabilitatea bunelor practici dezvoltate, evitarea suprapunerilor informa ionale şi promovarea cercetării ştiin ifice performante în domeniu, inclusiv asigurarea vizibilită ii na ionale şi interna ionale, şi constituirea unor comunită i de practici, ca formă de organizare şi facilitare a învă ării profesionale;

- Definirea unitară a unui pachet de competen e generale şi transversale de format în urma absolvirii unei forme de educa ie psihopedagogică ini ială destinată cadrelor didactice din învă ământul superior, precum şi a celui aferent sus inerii progresului în cariera didactică universitară;

- Stabilirea unor standarde de performan ă, pe baza pachetului de competen e generale şi transversale, care să facă posibilă evaluarea periodică a cadrelor didactice şi stabilirea nevoilor de formare continuă a acestora în domeniul didacticii specialită ii şi cel psihopedagogic.

\section{Referin e}

- Iucu, R., Borzea, A., \& Mironov, C., „Profesionalizarea carierei didactice în învă ământul superior: evolu ii şi provocări" (note de curs din proiectul POSDRU/57/1.3/S/26646, lider de parteneriat - Universitatea din Bucureşti).

- Ministerul Fondurilor Europene. (2018). Ghidul solicitantului „Bursa student antreprenor - măsură activă pentru creşterea participării studen ilor din categorii vulnerabile la programe de studii de licen ă", disponibil pe http://www.fonduriue.ro/presa/noutati-am-oi/details/6/425/am-pocu-lanseaz\%C4\%83-ghidulsolicitantului-\%E2\%80\%9Ebursa-student-antreprenor-m\%C4\%83sur\%C4\%83activ\%C4\%83-pentru-cresterea-participarii-studen $\%$ C $8 \% 9$ Bilor-din-categoriivulnerabile-la-programe-de-studii-de-licen $\% \mathrm{C} 8 \% 9 \mathrm{~B} \% \mathrm{C} 4 \% 83 \% \mathrm{E} 2 \% 80 \% 9 \mathrm{D}$.

- Ministerul Fondurilor Europene. (2015). Documentul Cadru de Implementare 
pentru POSDRU 2007 - 2013, versiunea 11, disponibil pe http://www.fonduriue.ro/images/files/programe/CU/POSDRU/dci.v11.pdf.

- Ministerul Fondurilor Europene. Programul Opera ional Capital Uman 2014 - 2020, disponibil pe http://old.fonduri-ue.ro/res/filepicker_users/cd25 a597fd-62/2014-2020/po/pocu/Programme_2014RO05M9OP001_1_4_en.pdf.

- Ministerul Muncii, Familiei şi Egalită ii de Şanse. Programul Opera ional Sectorial Dezvoltarea Resurselor Umane, disponibil pe http://old.fonduri-ue.ro/ posdru/images/downdocs/pos_dru11.pdf.

- Niklasson, L. (2015). Reorganization of Practicum in Initial Teacher Education: A search for challenges in implementation by ex-ante evaluation. Journal of Arts \& Humanities, 4(34).

- Singer, F., \& Sarivan, L. (2011). Masterprof: A Program to Educate Teachers for the Knowledge Society. Procedia - Social and Behavioral Science, disponibil pe www.sciencedirect.com. https://doi.org/10.1016/j.sbspro.2011.01.023.

The online version of this article can be found at: http://revped.ise.ro/category/2018-en/

\section{(c) BV-NC-EA}

This work is licensed under the Creative Commons Attribution-NonCommercial-ShareAlike 4.0 International License.

To view a copy of this license, visithttp://creativecommons.org/licenses/by-ncsa/4.0/ or send a letter to Creative Commons, $P O$

Box 1866, Mountain View, CA 94042, USA.
Versiunea online a acestui articol poate fi găsită la:http://revped.ise.ro/category/2018-ro/

\section{(cc) EY-Ne-sa}

Această lucrare este licen iată sub Creative Commons Attribution-NonCommercial-ShareAlike 4.0 International License.

Pentru a vedea o copie a acestei licen e, vizita $i$ http://creativecommons.org/licenses/by-nc-sa/4.0/ sau trimite i o scrisoare către Creative Commons, PO Box 1866, Mountain View, CA 94042, SUA. 